\title{
Construction Technique of Long-Span Shallow-Buried Tunnel Considering the Optimal Sequence of Pilot-Tunnel Excavation
}

\author{
Bao Jin, ${ }^{1,2}$ Yang Liu, ${ }^{1}$ Changxi Yang, ${ }^{1}$ Zhicheng Tan, ${ }^{1}$ and Jianyang Zhang ${ }^{1}$ \\ ${ }^{1}$ School of Transportation Science and Engineering, Harbin Institute of Technology, Harbin 150090, China \\ ${ }^{2}$ Jinan Urban Construction Group Co., Ltd, Jinan 250000, China \\ Correspondence should be addressed to Yang Liu; ly7628@hit.edu.cn
}

Received 30 April 2015; Revised 30 June 2015; Accepted 1 July 2015

Academic Editor: Robert Cerný

Copyright (c) 2015 Bao Jin et al. This is an open access article distributed under the Creative Commons Attribution License, which permits unrestricted use, distribution, and reproduction in any medium, provided the original work is properly cited.

Construction technique considering the optimal sequence of pilot-tunnel excavation was investigated in order to ensure the safety of construction process of long-span shallow-buried tunnel. Firstly, optimal comparisons of the effect of different sequence of pilot-tunnel excavation on the ground settlement were implemented by the numerical analysis. Secondly, an optimal construction method was determined and applied to the construction of a practical tunnel. Some key issues and procedure of the selected construction method were described in detail. Finally, the numerical modeling and calculation of the tunnel construction process were conducted, and the effectiveness of these simulations was demonstrated by using the measured data of the practical tunnel.

\section{Introduction}

The selection of the tunnel construction methods should take account of the section shape, the tunnel length, the engineering geology, and the environmental factors [1]. Due to the poor geological condition like fragile surrounding rock, the abundance of surface and ground water, the construction difficulty, and the high possibility of collapse, urban longspan tunnels are usually constructed by shallow subsurface excavation method [2], which includes the underground pilot-tunnel excavation and the supporting system and lining construction [3]. Aiming to the long-span shallow-buried tunnel, the main construction methods could be sorted as center diaphragm method (CDM), cross diaphragm method (CRDM), double side drift method (DSDM), and threebench method (TBM) [4-6].

Usually, CDM, CRDM, and DSDM are applied to projects with unstable tunnel headings, shallow-buried depth, and fragile surrounding rocks, with the delicately divided vertical sections ensuring the stability of headings and the small fragment of surrounding rocks [7-9]. For CDM, the simple construction process, the short construction time, and the low costs contribute to its popularity, while, due to the existence of the diaphragm, the working space narrows down for only small-medium size machines [10]. For CRDM, every construction phase is a complete system with reasonable stress, small distortion, and high security [11]. Also, according to massive measured data, projects using CRDM could reduce near $50 \%$ ground surface settlements compared to CDM $[12,13]$. For DSDM, the pilot tunnels could ascertain the geological condition ahead to guarantee the precautions, enhancing the high security while causing the complex construction process, expensive costs, slow construction speed, and poor condition for large machines [14]. For TBM, the distributed parallel excavation and primary support for the arch wall are conducted, and the advanced supports of the concrete tunnel invert are closed in time for the stable primary supporting system, defending the natural bearing capacity of the surrounding rocks and effectively restraining the deformation $[15,16]$.

The remainder of this paper is organized as follows. The optimization comparison of the tunnel construction method is discussed, considering the different security situation of the diverse excavation procedure of the pilot tunnel. Furthermore, the selected optimal construction method is applied to a practical long-span shallow-buried tunnel under construction, and the details of the construction procedure are described. Finally, provided the chosen method, the numerical modeling and calculation of the tunnel construction 
are conducted, and the effectiveness of these simulations is validated by using the measured data of this practical tunnel.

\section{Optimization Comparison of Different Sequences of Pilot-Tunnel Excavation}

The shallow-buried excavation method was applied in the tunnel, with the large sectional area over $100 \mathrm{~m}^{2}$. The main selection standards of the optimal excavation methods were to prevent the tunnel collapse and control the ground displacement. In order to take the structural deformation of the tunnel and the ground settlements into strict control, multipilot-tunnel CRDM was used for the excavation, with 6 pilot tunnels for the whole tunnel and 2 benches for each pilot tunnel. For multi-pilot-tunnel construction, the sequence of pilot-tunnel excavation has influence on the ground settlements. Therefore, through the comparison of different sequences of pilot-tunnel excavation, the optimal method could be achieved with the minimum ground settlements and the shortest construction schedule. Although the tunnel deformation and settlements could be well controlled by successive excavation, the problems like long construction period and low economic benefits would appear. Thus, in the interest of improving the excavation speed, the following three simultaneous multi-pilot-tunnel excavation methods were analyzed and compared for the optimal one $[17,18]$.

Method 1. Pilot tunnels number 1, number 3, and number 5 would be simultaneously excavated first and then pilot tunnels number 2 , number 4 , and number 6 , with $10 \mathrm{~m}$ delay and temporary vertical diaphragm between the adjacent pilot tunnels, $3 \mathrm{~m}$ delay and horizontal diaphragm between the top and bottom pilot tunnels.

Method 2. Pilot tunnels number 1 and number 6 would be simultaneously excavated first, then pilot tunnels number 2 and number 5, and finally pilot tunnels number 3 and number 4 , with $6 \mathrm{~m}$ delay and temporary vertical diaphragm between the adjacent pilot tunnels, $3 \mathrm{~m}$ delay and horizontal diaphragm between the top and bottom pilot tunnels.

Method 3. Pilot tunnels number 2 and number 5 would be simultaneously excavated first, then pilot tunnels number 1 and number 6 , and finally pilot tunnels number 3 and number 4 , with $6 \mathrm{~m}$ delay and temporary vertical diaphragm between the adjacent pilot tunnels, $3 \mathrm{~m}$ delay and horizontal diaphragm between the top and bottom pilot tunnels.

Method 1 is an interval excavation method for pilot tunnels, reducing the excavation interaction of the adjacent pilot tunnels and accelerating the construction speed by simultaneous multi-pilot-tunnel excavation. Method 2 is a successive excavation method from both sides to the center of the section for pilot tunnels, acquiring favorable control of the ground settlements of the central part of the large section while causing the close delay of the tunnel headings for closing the construction of the second lining supports in time. In Method 3, the inner pilot tunnels were excavated first and then the external pilot tunnels and the central pilot

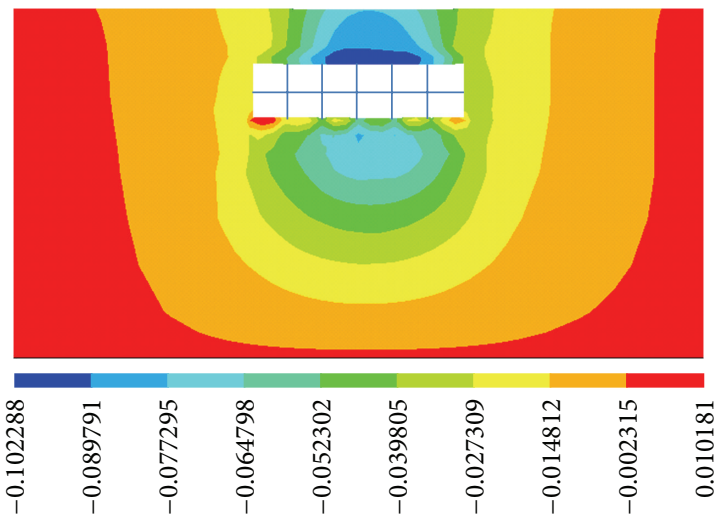

Figure 1: Vertical displacement nephogram of Method 1.

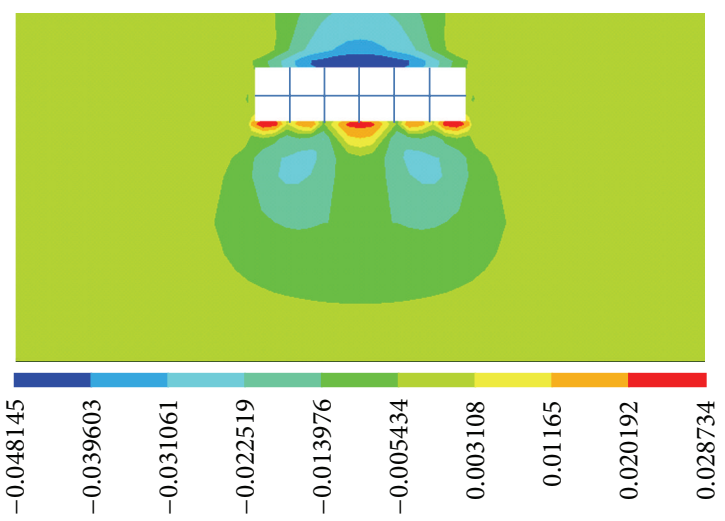

Figure 2: Vertical displacement nephogram of Method 2.

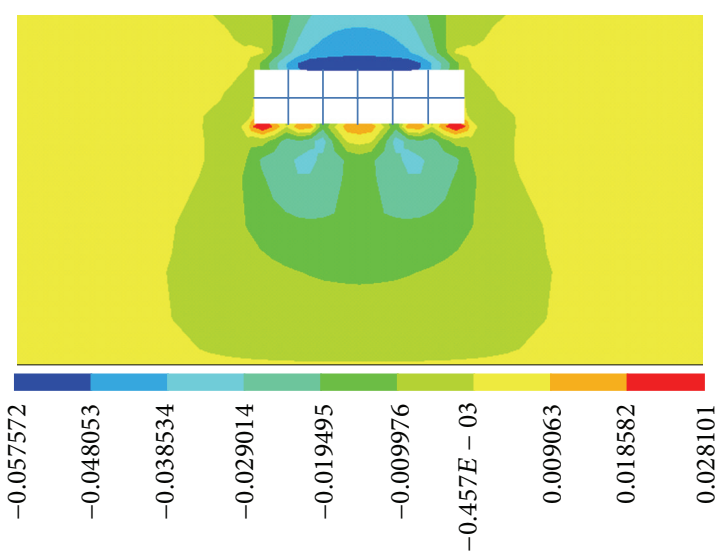

Figure 3: Vertical displacement nephogram of Method 3.

tunnels. By the finite element simulation analysis, the optimal construction method could be found.

The FEM analysis and comparison were conducted to the methods above with ANSYS, using the Element Birth and Death technique for the simulation of the continuous excavation and supports of the tunnel. The vertical displacement nephograms of the excavation methods above are shown in Figure 1 to Figure 3, the ground settlement curves are shown 


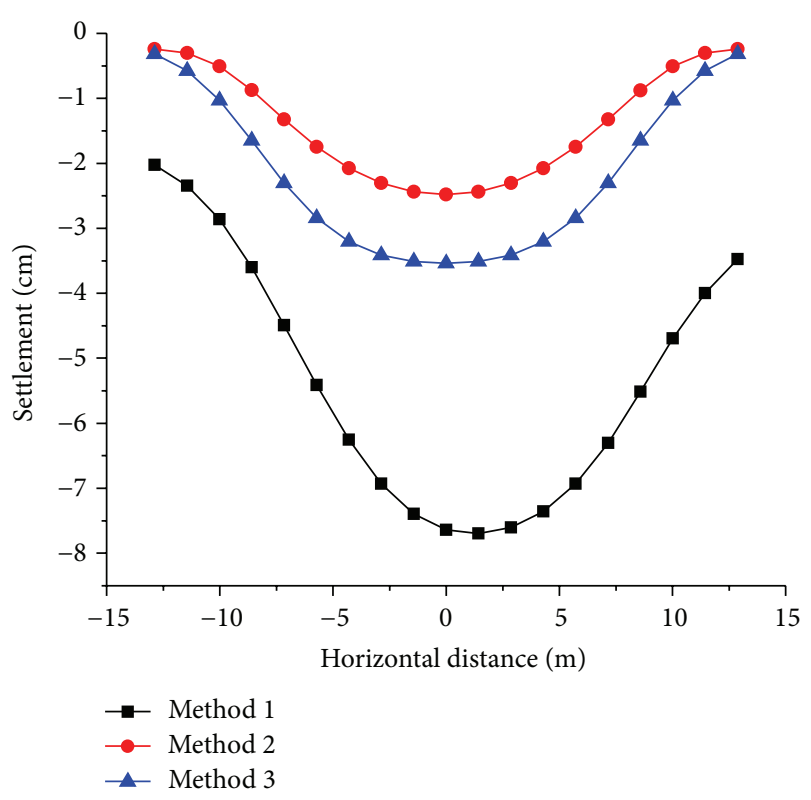

Figure 4: Ground settlement curves.

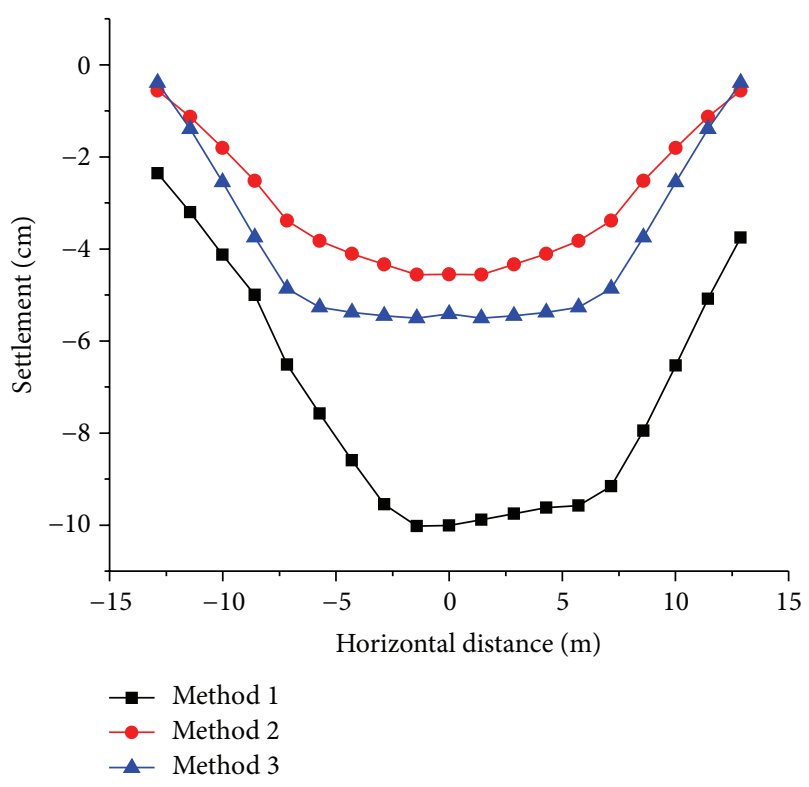

FIgURE 5: Arch apex displacement curves.

in Figure 4, and the arch apex displacement curves are shown in Figure 5.

From the vertical displacement nephograms, Method 2 holds the minimum ground disturbance and then Method 3, and Method 1 holds the maximum vertical displacement. From the ground settlement curves and the arch-apex displacement curves, the same results could be obtained. Therefore, Method 2 should be the optimal method for the tunnel excavation.

\section{Key Issues of Selected Optimal Construction Technique of Long-Span Shallow-Buried Tunnel}

Based on the optimal analysis of Section 2, an optimal construction method of long-span shallow-buried tunnel is determined and applied to a practical tunnel under construction. Some key construction steps and the details of the construction procedure are described as follows.

3.1. Brief Introduction of a Practical Long-Span Shallow-Buried Tunnel. The tunnel of Chuanluoyuan Street is a long-span shallow-buried rectangle tunnel which is located in Jinan China. It is in the south of Quancheng Square and north of Luowen Street. The width of excavation is $25.2 \mathrm{~m}$, the height is $6.9 \mathrm{~m}$, and the length is $67 \mathrm{~m}$. The tunnel is a structure of reinforced concrete frame, including construction shaft, cross-passageway, and the main tunnel. A construction shaft has been built in the west of Luowen Street, the clearance of which is $5 \mathrm{~m} \times 7.7 \mathrm{~m}$.

This tunnel is under the intersection of Luoyuan Street and Luowen Street, which carries amounts of traffic flow. Additionally, many kinds of pipelines were constructed under the surface of road. Owing to the influence of above factors, the stress field of this tunnel is complex. Meanwhile, the underground springs and conglomerate layer have enhanced the difficulty of construction.

\subsection{Key Construction Steps}

3.2.1. Previous Supporting for Large Pipe Shed. In order to improve the strength of the surrounding rock, decrease the settlement, and ensure the safety of pipeline inside, it is recommended to construct large pipe shed before the main project. The pipe shed for the cross-passageway could be built on the vertical shaft, and the pipe shed for the main tunnel could be built on the cross-passageway. After finishing large pipe shed, construct a cage with twisted steel. 42.5 ordinary Portland cement was chosen in this project. The water-cement ratio was from $0.8: 1$ to $1: 1$, and the pressure was $0.2-0.5 \mathrm{MPa}$. The grouting process was carried out from two sides to center.

3.2.2. Full-Section Grouting. To improve the stability of the tunnel face and decrease settlement caused by water seepage, block off the tunnel face every $5 \mathrm{~m}$. I16 steel was chosen in this process, and the width of C25 shot-concrete is $10 \mathrm{~cm}$. Every grouting pipe was $6 \mathrm{~m}$ long and the interval between two pipes was $60 \mathrm{~cm}$. The paste was made up of cement and sodium silicate.

3.2.3. Grouting with Small Pipe. Grouting with small radial pipes to reinforce the tunnel could further fill up the interspace between initial supporting structures and surrounding rocks, recover the stress of soil, decrease settlement of tunnel crown, strengthen rocks below, improve the stability of the structure, and decrease settlement caused by disturbance. Specifically, workers set small grouting pipes vertically at 
the tunnel crown, flank, and bottom. The grouting pipes were $0.5 \mathrm{~m}$ embedded into initial supporting structures. Every grouting pipe was $2 \mathrm{~m}$ long and the interval of two pipes was $100 \mathrm{~cm}$. The purpose of grouting at tunnel flank and arch was to prevent collapse and sand leaking. At the same time, it could also improve the stability and strengthen the rocks. Grouting at locking anchor could improve the bearing capacity of the locking, enlarge the foundation, and decrease the self-settlement as well as the ground settlement.

3.3. Procedure of Selected Constructed Method. Construction of main tunnel began from one side of the cross-passageway. According to CRD method, the cross section was divided into 6 pilot tunnels numbered from 1 to 6 and added up to 12 tunnels. Considering the structure characteristic, pilot tunnels 1 and 6 were constructed firstly to control the settlement, followed by tunnels 2 and 5. Tunnels 3 and 4 were constructed at last.

During the construction process, the upper step was excavated $3 \mathrm{~m}$ in advance of the lower step. The core soil of the upper step was kept. The temporary supports between two pilot tunnels were built by using I25a steel I-beam combined with shot-concrete, and the distance between two temporary supports was $50 \mathrm{~cm}$. Artificial excavation and air pick excavation was adopted in this procedure. The steel bracing was set every $50 \mathrm{~cm}$ excavation and the $\Phi 42$ locking anchor was $3 \mathrm{~m}$ long. The blocking off, grouting, and other procedures were done as presented in Section 3.2. Then set the tunnel flank formwork. Dismantle the temporary horizontal supporting structure of tunnels 1 to 6 , and the length is no longer than $6 \mathrm{~m}$ each time dismantling. Build the secondary lining then. Measurement and monitoring should be taken frequently to acquire information in time and guide the construction efficiently.

The whole procedure of the construction method consists of six steps, which are described as follows.

Step 1. Set the large pipe shed outside the initial supporting structure and grout to reinforce the stratum.

Step 2. Excavate the pilot tunnels 1 and 6 with step method. Build the initial supporting structure and reinforce the corner with locking anchor (grout with small radial pipes in time).

Step 3. Excavate the pilot tunnels 2 and 5 with step method, $6 \mathrm{~m}$ behind tunnels 1 and 6 . Build the initial supporting structure and reinforce the corner with locking anchor. Excavate the pilot tunnels 3 and 4 with step method, $6 \mathrm{~m}$ behind tunnels 2 and 5. Build the initial supporting structure and reinforce the corner with locking anchor.

Step 4. Build the waterproof layer in 1 a to $6 a$ and the secondary lining.

Step 5. Dismantle the temporary supporting structure of tunnels 1 and 6 (the length is no longer than $6 \mathrm{~m}$ each time dismantling). Set the tunnel flank formwork and build the flank and roof of tunnels 1 and 6. Build the column, waterproof layer, and roof of tunnels 2 to 5 .
Step 6. Dismantle the temporary supporting structure of all tunnels and build the secondary lining of remaining parts and grout.

The construction sequence of main tunnel is shown in Figure 6.

\section{Numerical Modeling and Calculation of Tunnel Construction}

ANSYS software is used for simulated analysis of the excavation, which would show whether the construction method is rational. It could also determine the stability of the surrounding rock and the parameters of the supporting and give feedback in time as well. This would further decrease the settlement and disturbance, guarantee safety in construction, and ensure availability of other transport facilities.

Based on page 34 of [19], some basic assumptions during modeling are listed below.

(1) The ground is regarded as horizontal, and the soil layers are assumed homogeneous and continuous horizontal layers.

(2) Although there is abundant groundwater and high groundwater level, the constructors have built dewatering well, so it is reasonable to ignore the groundwater effect.

(3) The parameters of the soil layer are determined according to the geological survey data, and the parameters of the supporting are determined according to the strength of materials.

Table 1 shows the physical and mechanical parameters of surroundings and supporting system.

Following conclusions could be obtained by theoretical analysis. When excavating in the soil layer, which is homogeneous, elastic, and boundless, release of load would affect stress and displacement of soil around the tunnel. The difference would be less than $1 \%$ beyond 3 times the tunnel diameter and less than $5 \%$ beyond 3 times the tunnel diameter. Therefore, the analysis region is a rectangle. The width of the rectangle is 7 times the tunnel span. The distance between tunnel apex and the top margin of the rectangle is the depth of the tunnel. The distance between the tunnel bottom and the bottom margin of the rectangle is 3 times the tunnel height.

The soil mass is simulated with solid 45 entity elements. The large pipe shed, the previous small pipe, and the preliminary supporting is also simulated with entity elements. To simulate the construction procedure of preliminary supporting, it is advisable to change the characteristics of material. In order to increase the efficiency of analysis, shell elements should be used to simulate second lining and the temporary supporting. Reinforcement of large pipe shed and previous small pipe changed the properties of the soil mass, and this procedure has been finished before excavation. The planar model is established and divided into elements firstly. The model is stretched along the tunnel axis then. As a result, the entity model of tunnel and soil layer is obtained. The material 
TABle 1: Parameters of surroundings and supporting system.

\begin{tabular}{|c|c|c|c|c|c|}
\hline Parameter type & $\begin{array}{c}\text { Elastic modulus } \\
(\mathrm{MPa})\end{array}$ & $\begin{array}{l}\text { Poisson's } \\
\text { ratio }\end{array}$ & $\begin{array}{c}\text { Internal friction angle } \\
\text { (Celsius degree })\end{array}$ & $\begin{array}{c}\text { Cohesion } \\
(\mathrm{kPa})\end{array}$ & $\begin{array}{r}\text { Density } \\
\left(\mathrm{kg} / \mathrm{m}^{3}\right) \\
\end{array}$ \\
\hline Miscellaneous fill & 3.1 & 0.35 & 12.0 & 8.0 & 1929 \\
\hline Clay & 5.0 & 0.33 & 22.5 & 20.5 & 1918 \\
\hline Gravel soil & 23 & 0.18 & 30.0 & 5.0 & 2041 \\
\hline Gabbro eluvial soil & 7.0 & 0.32 & 26.4 & 15.0 & 1939 \\
\hline Large pipe shed & 2000 & 0.2 & - & - & 3000 \\
\hline Supporting structure & 28000 & 0.2 & - & - & 2549 \\
\hline
\end{tabular}

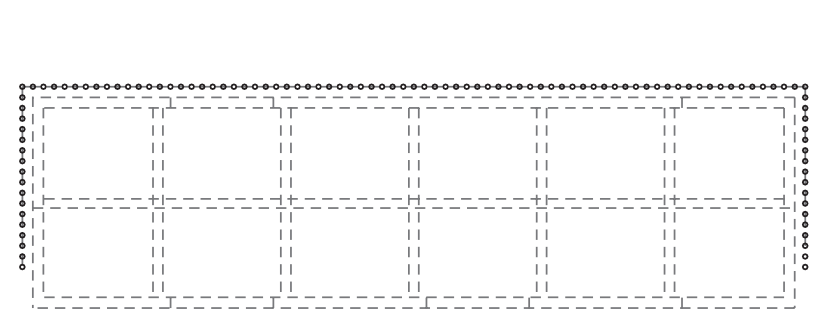

(a) Step 1

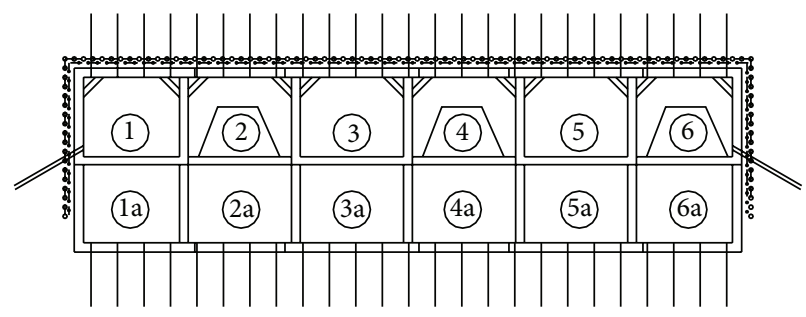

(c) Step 3

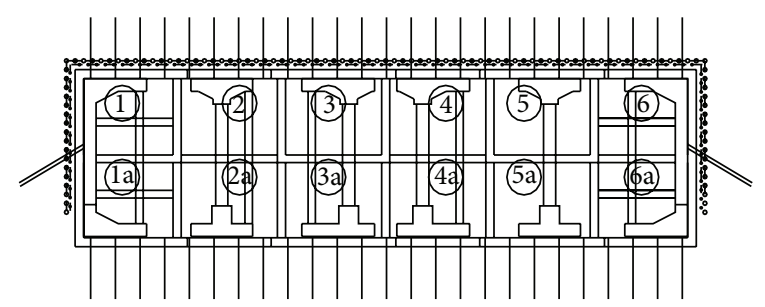

(e) Step 5

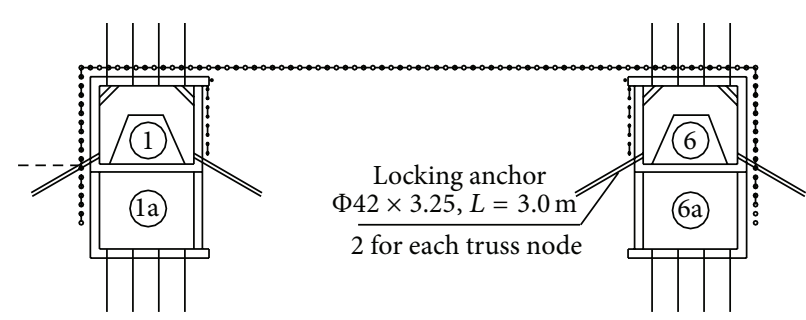

(b) Step 2

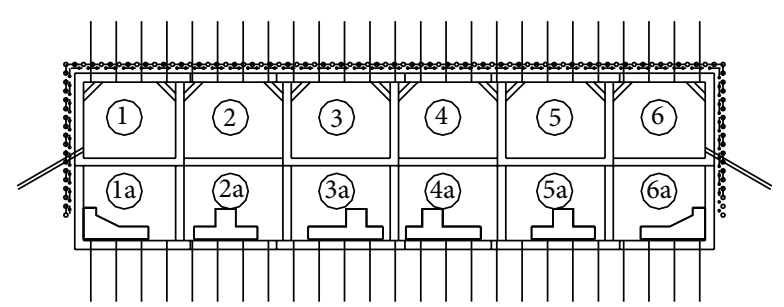

(d) Step 4

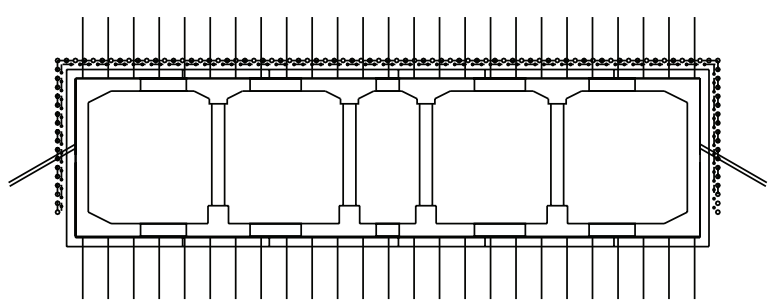

(f) Step 6

FIGURE 6: Flow chart of construction method.

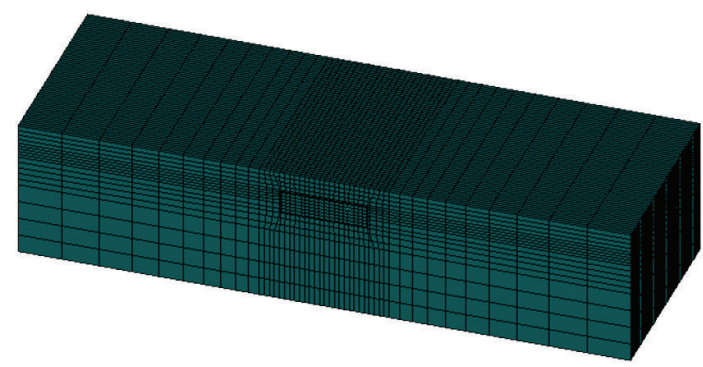

FIgURE 7: Tunnel finite element model.

parameters of the elements need to be modified next. All these procedures are shown in Figure 7.
The initial stress is made up of gravity stress and tectonic stress. The cause of tectonic stress is complex, and the error of data acquired is large. Considering that the tunnel is shallow buried, only gravity stress is taken into account.

One excavation procedure includes two calculation steps. The first calculation step is the simulation of excavation process, surrounding-rock load, and deformation released with no support; the second calculation step is the simulation of liner construction, surrounding-rock load released continuously with support. Presuming that initial support bears seventy percent of load after finishing excavating the tunnel, the upper half of tunnel's load is totally released while the bottom half of tunnel's load is released to seventy percent, considering the shallow-buried tunnel. Load should be 


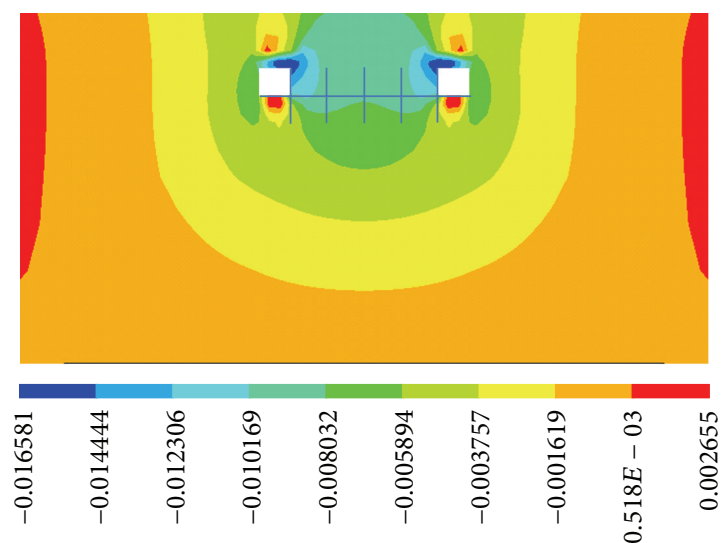

(a) Vertical displacement nephogram of Step 1
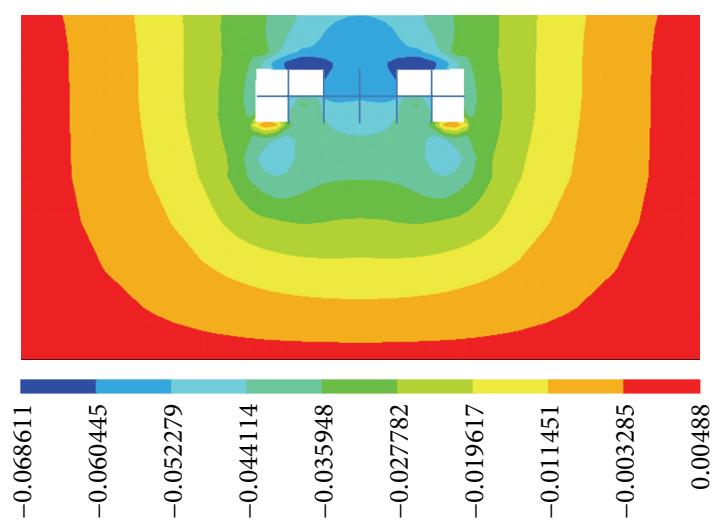

(c) Vertical displacement nephogram of Step 3

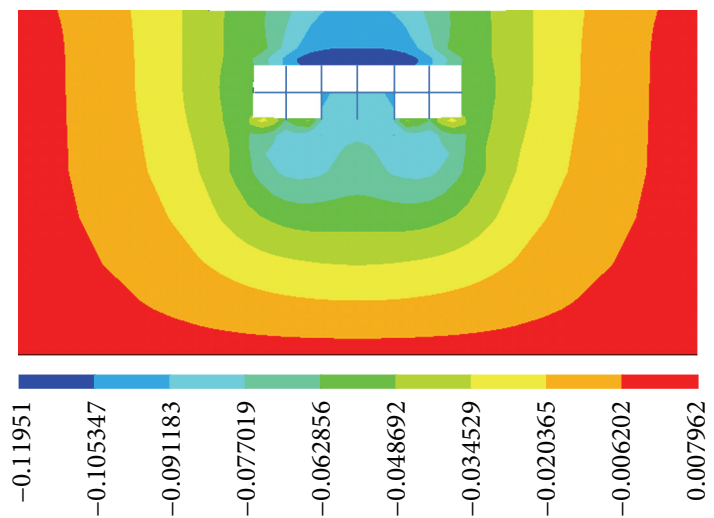

(e) Vertical displacement nephogram of Step 5

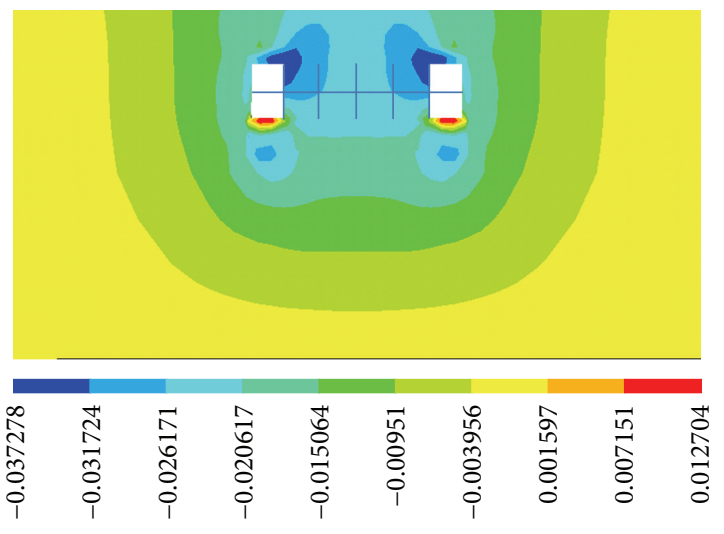

(b) Vertical displacement nephogram of Step 2

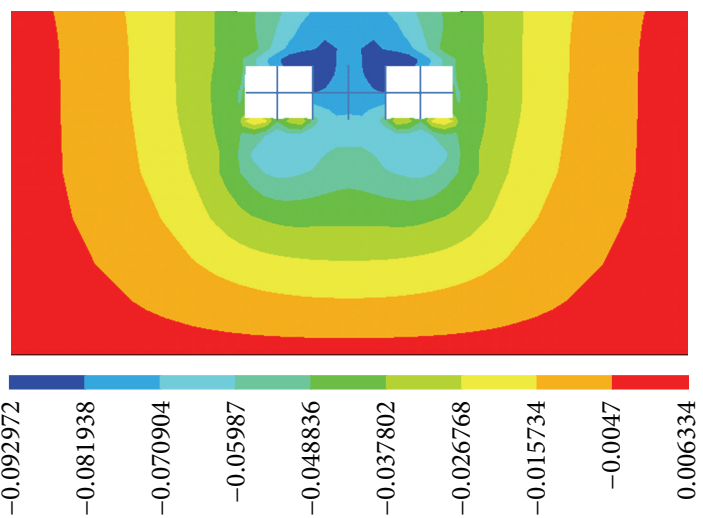

(d) Vertical displacement nephogram of Step 4

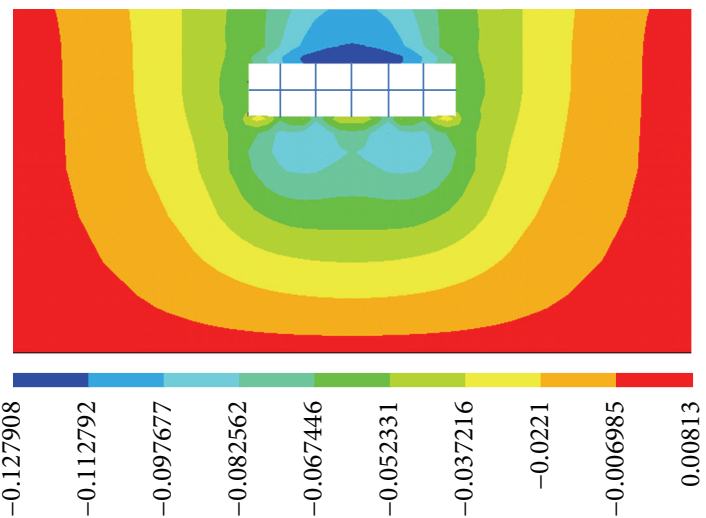

(f) Vertical displacement nephogram of Step 6

Figure 8: Vertical displacement nephograms of each step.

released by several steps when excavating multi-pilot-tunnel. The vertical displacement nephograms of each step are shown in Figure 8.

To verify the accuracy of the FEM, Peck, the major formula applied in the settlement prediction of the current tunnel engineering, has been used to calculate the ground settlement for the comparison with the FEM computing results. Consider

$$
s(x)=S_{\max } \exp \left(-\frac{x^{2}}{2 i^{2}}\right),
$$

where $s(x)$ represents settlement, $S_{\max }$ is the maximum settlement, $x$ is the distance to the central line of tunnel, and $i$ is the parameter of the width of settlement. Otherwise, $S_{\max }$ and $i$ are defined as follows:

$$
\begin{aligned}
S_{\max } & =\frac{V}{\sqrt{2 \pi} i}, \\
i & =\frac{Z}{\sqrt{2 \pi} \operatorname{tg}\left(45^{\circ}-\phi / 2\right)},
\end{aligned}
$$

where $V$ is the loss of ground layer per meter. 


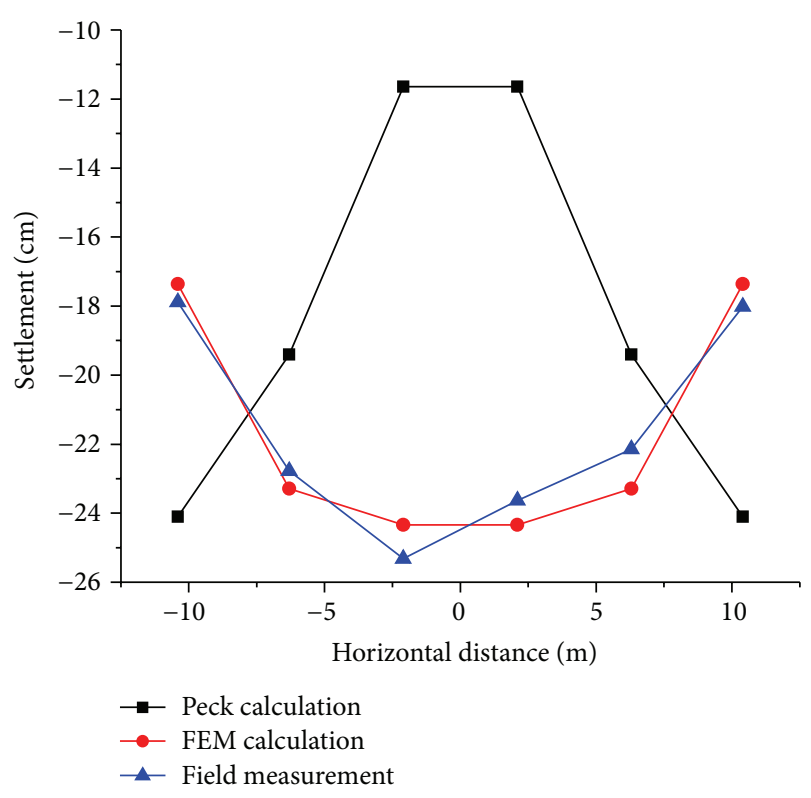

FIGURE 9: Curves comparison of ground settlement.

The value of $i$ is related to $Z$ (the depth of tunnel) and $\phi$ (the inner friction angle of soil). In this project, the ground settlement has been compared between pilot tunnels number 1 and number 6 which have been currently excavated, and the values of the relevant parameters are as follows: $Z=9.5 \mathrm{~m}$, $\phi=25^{\circ}$, according to the local construction experience, the ratio of the loss of ground layer values $1.2 \%$, and the excavation volume of the pilot tunnel per meter is $6.95 \times 4.3=$ $29.885 \mathrm{~m}^{3}$.

According to Peck, the maximum settlement of pilot tunnels number 1 and number 6 is $24.10 \mathrm{~mm}$, while the field monitoring data are $18.02 \mathrm{~mm}$ and $17.89 \mathrm{~mm}$, and the FEM calculation result is $17.36 \mathrm{~mm}$. The curves comparison of ground settlement is shown in Figure 9.

From the settlement data and curves above, it is obvious that great problems lie in the Peck prediction of this tunnel excavation, mainly due to the application of presupporting with large pipe shed and small pipe grouting, which cannot be considered by Peck, while the FEM has fully considered the construction technology and procedure, leading to the similar calculation results with filed measurement. Therefore, the numerical simulation of this tunnel is relatively accurate, and the selection of each parameter is reasonable. The calculation results could be guidance for the future construction.

\section{Conclusions}

Based on a shallow-buried tunnel project, the research of the construction techniques of long-span shallow-buried tunnel considering the optimal sequence of pilot-tunnel excavation was conducted. Through the research, the following conclusions were acquired.

(i) With shallow-buried depth and weak surrounding rocks, the main factors affecting the stability of the long-span tunnels are the construction method, the excavation procedure, the underground water, and so forth. Relevant measures should be taken to ensure the deformation of the surrounding rocks in a practical project.

(ii) The selection of the optimal excavation method for the shallow-buried tunnels should meet the following qualifications: the adaptation for the potential change of the geological and hydrological conditions, the geometrical features and the operational functions of tunnel design, and the special requirements of the specific projects.

(iii) Through the analysis of the vertical displacement nephograms of the optimal excavation method, the primary support optimization could be achieved for the tunnel excavation.

\section{Conflict of Interests}

The authors declare that there is no conflict of interests regarding the publication of this paper.

\section{Acknowledgment}

The authors thankfully acknowledge the support of this work by Heilongjiang Province Natural Science Foundation (Grant no. E080509).

\section{References}

[1] J. Chen, Y. Zhu, and M. Li, "Novel excavation and construction method of an underground highway tunnel above operating metro tunnels," Journal of Aerospace Engineering, pp. 1-2, 2014.

[2] V. Manassero and G. Di Salvo, "Two difficult tunnelling problems solved by using permeation grouting: the excavation of submerged large size tunnels for roma and napoli metro projects," in Proceedings of the 4th International Conference on Grouting and Deep Mixing, pp. 1972-1984, February 2012.

[3] C. Shi, L. Peng, and J. Li, "Study on the stratum deformation caused by tunnel excavation with different division of crosssection," in Recent Advancement in Soil Behavior, in Situ Test Methods, Pile Foundations, and Tunneling, pp. 262-264, American Society of Civil Engineers, 2009.

[4] C. Wu and Z. Ding, "Effect of mechanics and optimum process in excavating multi-arch tunnel," in Recent Advancement in Soil Behavior, in Situ Test Methods, Pile Foundations, and Tunneling, pp. 281-283, 2009.

[5] L. Wang, H. Hu, and S. Wang, "Study on construction methods for tunnels of large cross-section excavated in weak rocks," in Recent Advancement in Soil Behavior, in Situ Test Methods, Pile Foundations, and Tunneling, pp. 225-229, American Society of Civil Engineers, 2009.

[6] M. Alhaddad and M. Wilcock, "Multi-suite monitoring of an existing cast iron tunnel subjected to tunnelling-induced ground movements," in Proceedings of the Geo-Shanghai International Conference, pp. 293-294, May 2014, Shanghai, China.

[7] M. I. Junica, D. Tsuyoshi, and N. Kazuo, "Multi-shield excavation for a large rectangular-shaped tunnel," in Proceedings of the Soft Ground Technology Conference, pp. 460-462, 2015. 
[8] Y. Li, C. Han, and C. Ai, "Study on safety stability of excavating shallow depth neighborhood tunnel in traversing construction," in Proceedings of the 9th International Conference of Chinese Transportation Professionals (ICCTP '09), pp. 2188-2189, Harbin, China, August 2009.

[9] J. Hill and G. Boonstra, "Drilling and grouting of water bearing rock formations to facilitate tunnel excavation," in Proceedings of the 4th International Conference on Grouting and Deep Mixing, pp. 798-804, February 2012.

[10] H. Li, Z. Zhang, and C. Kan, "Numerical analysis on an excavation method comparison for a shallow-buried large-span tunnel," in Proceedings of the International Conference on Pipelines and Trenchless Technology (ICPTT '14), pp. 732-736, Xiamen, China, November 2014.

[11] F. Xue, J. Ma, and L. Yan, "Three-dimension FEM analysis of large cross-section tunnel in collapsible loess constructed by CRD method," in GeoFlorida 2010: Advances in Analysis, Modeling \& Design, pp. 2349-2351, American Society of Civil Engineers, 2010.

[12] Z. Yang, H. Huang, and D. Zhang, "Analysis on ground deformation caused by tunneling of large-diameter tunnel boring machine," in Deep and Underground Excavations, pp. 327-328, American Society of Civil Engineers, 2010.

[13] S. Chen, S. Lee, and W. Yang, "Numerical analysis of ground settlement induced by a double-o-tube (dot) shield tunnel excavation," in Proceedings of the 4th International Conference on Transportation Engineering (ICTE '13), pp. 949-958, October 2013.

[14] W. Yang, L. Peng, and L. Wang, "Method of ground settlement prediction in urban tunnel construction based on ARMA," in Recent Advancement in Soil Behavior, in Situ Test Methods, Pile Foundations, and Tunneling, pp. 270-271, American Society of Civil Engineers, 2009.

[15] Y. An and L. Peng, "Simulation of a new construction method in a shallow-buried weak tunnel," in Proceedings of the Recent Advancement in Soil Behavior, in Situ Test Methods, Pile Foundations, and Tunneling, pp. 256-261, August 2009.

[16] F. Tonon, "Methods for enlarging transportation tunnels while keeping tunnels fully operational," Practice Periodical on Structural Design and Construction, vol. 15, no. 4, pp. 248-271, 2010.

[17] X. Weng, H. Ma, and J. Wang, "Stress monitoring for anchor rods system in subway tunnel using FBG technology," Advances in Materials Science and Engineering, vol. 2015, 7 pages, 2015.

[18] J. Liu, D. Liu, and K. Song, "Evaluation of the influence caused by tunnel construction on groundwater environment: a case study of Tongluoshan tunnel, China," Advances in Materials Science and Engineering. In press.

[19] R. B. Peck, "Deep excavations and tunneling in soft ground," in Proceedings of the 7th International Conference on Soil Mechanics and Foundation Engineering, pp. 225-290, Mexico City, Mexico, 1969. 

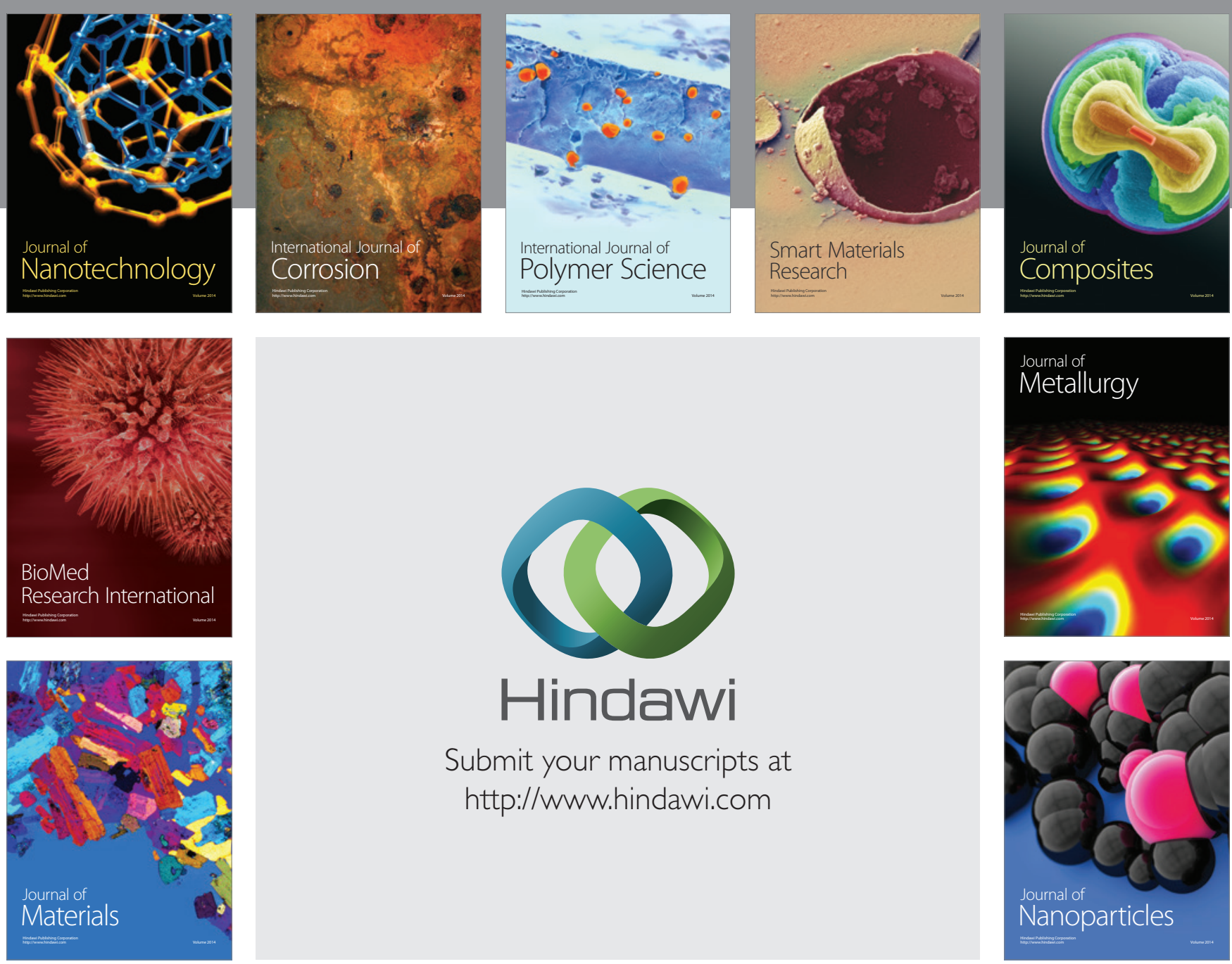

Submit your manuscripts at http://www.hindawi.com
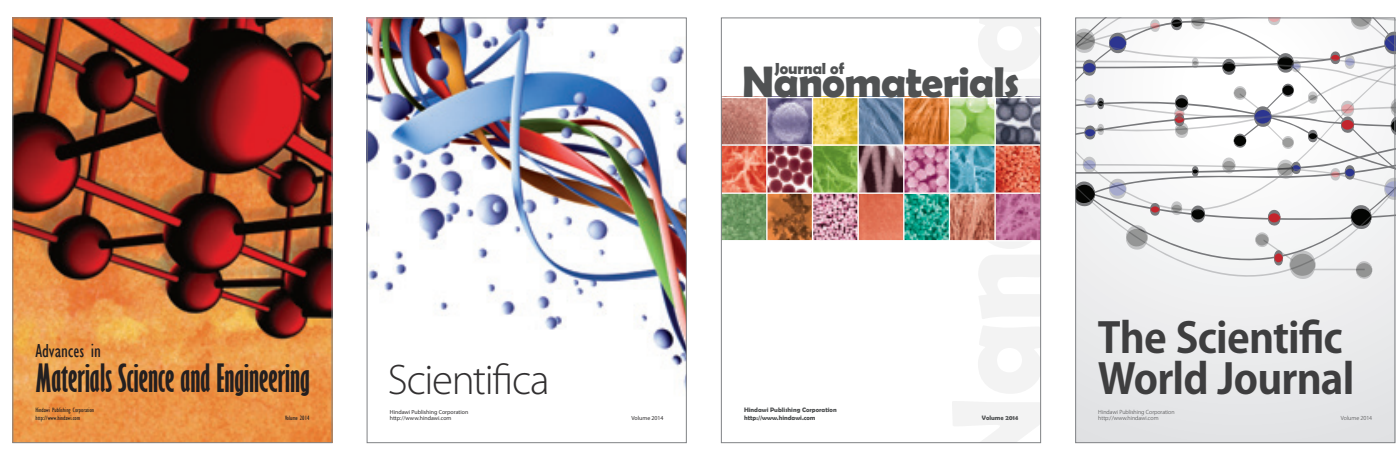

\section{The Scientific World Journal}
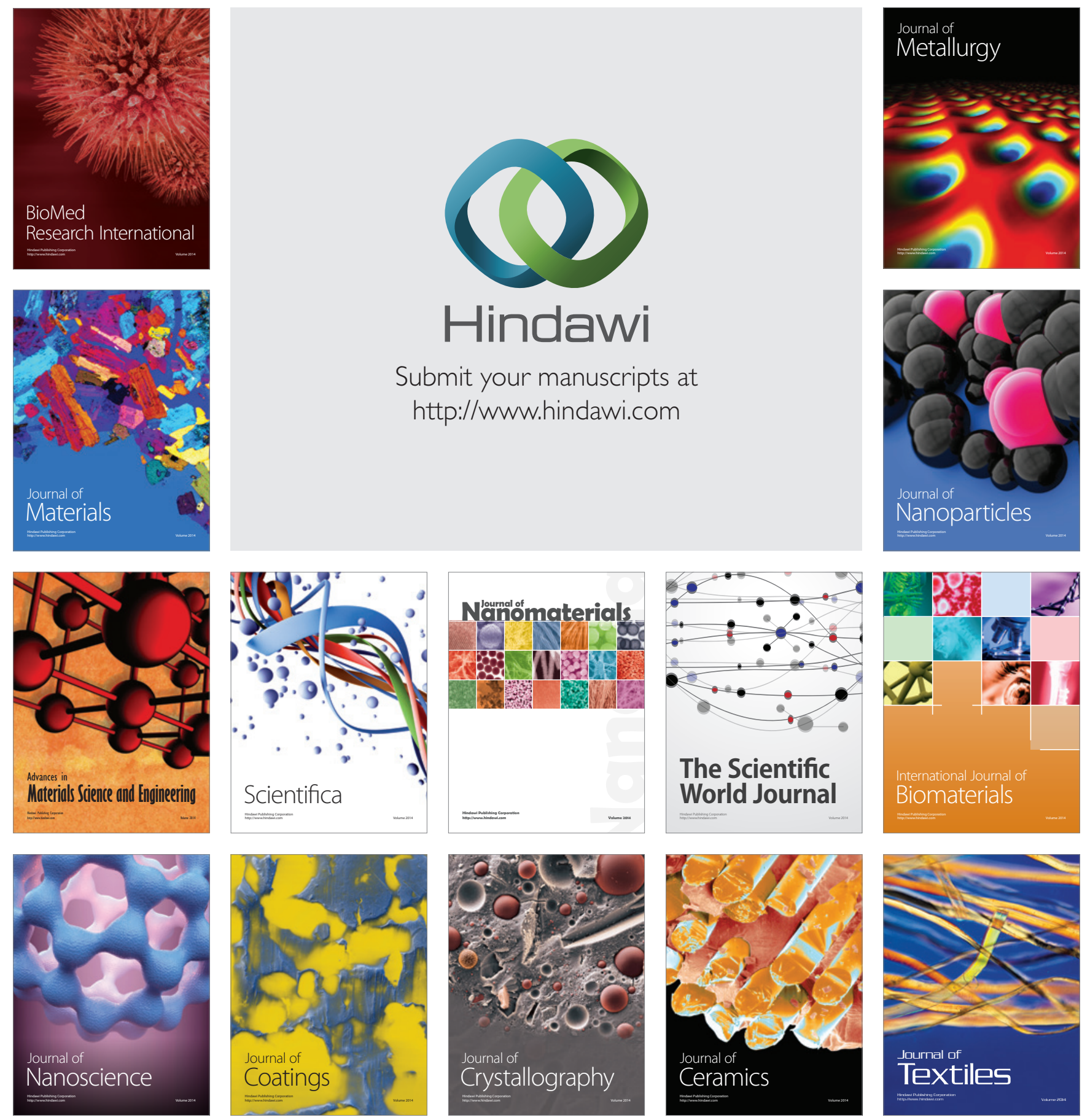